\title{
Elution Behavior of Protein and Pullulan in Asymmetrical Flow Field-flow Fractionation (AsFlFFF)
}

\author{
Eunsun Ji, Seong-Ho Choi, Kuk Ro Yoon, Jong-Han Chun, ${ }^{\dagger}$ and Seungho Lee* \\ Department of Chemistry, Hamam University, Daejeon 306-791, Korea. "E-mail: slee@hamam.ac.kr \\ "Department of Applied Chemistry, Hanbat University, Daejeon 305-719, Korea \\ Received July 11, 2006
}

\begin{abstract}
$\Lambda \mathrm{n} \Lambda \mathrm{sFFFF}$ channel was designed and built, and then tested for analysis of pullulans and proteins. Pullulans and proteins having various nominal molecular weights were injected at various conditions of the cross-tlow rate $\left(F_{v}\right)$ and the channel-out flow rate $\left(F_{\text {eut }}\right)$. The retention (measured by the retention ratio $R$ ) and the zone broadening (measured by the plate height $H$ ) were measured, and then compared with theory. When the incoming flow rate, $F_{\text {in }}$ (and thus $F_{\text {cut }}$ ) was varied with $F_{0}$ fixed at $2.5 \mathrm{~mL} / \mathrm{min}$, the plate height measured for the pullulan with nominal molecular weight $(M$ ) of about 100,000 showed the trend expected by the "longitudinal diffusion" theory ( $H$ decreases with increasing flow rate). In contrast, when $F_{\text {cut }}$ was varied with the flow rate ratio, $F_{V} / F_{\text {outt }}$, fixed constant at 5 , the plate height measured for the same sample showed the trend expected from the "non-equilibrium" theory ( $H$ increases with increasing flow rate). Calibration plots $(\log D$ vs. $\log M$ obtained with pullulans and proteins were not coincide, probably due to the difference in molecular conformation, suggesting the analysis of pullulans and proteins using $\Lambda$ SFIFFF requires independent calibration. It was found that the linearity of the protein-calibration plot was improved by using a buffer solution as the carrier.
\end{abstract}

Key Words : Asymmetrical flow-field flow fractionation (AsFIFFF), Protein, Pullulan, Plate height, Calibration

\section{Introduction}

In field-flow fractionation (FFF), the field-induced migration of the sample toward the accumulation wall is counteracted by diffusion of the components away from the wall, and the counteraction of these two opposing migrations results in formation of an equilibrium layer of the sample.!

In flow FFF (FIFFF), the field-induced migration velocities are same for all the injected components, and the mean layer thicknesses of the equilibrium layers of the components are determined only by the diffusion coefficients of the components. FIFFF thus allows determination of the diffusion coefficient of the sample from its retention data. ${ }^{2}$ At the beginning, the flow FFF was developed with a symmetrical channel, where both the upper and lower walls of the channel are porous, allowing the liquid flow to enter through the upper wall and an equal amount of flow ("crossflow") to exit through the lower (accumulation) wall. In order to simplify the channel construction and operation and to avoid the flow imperfections caused by the walls, the asymmetrical channel was introduced (Asymmetrical flow FFF). ${ }^{3}$ With this design, the porous upper wall is substituted by a glass wall, and the cross-flow is created when the carrier liquid exits via the accumulation wall as well as the channel outlet.

The applicability of FIFFF has been shown for analysis of various water-soluble and biological macromolecules such as proteins, ${ }^{+}$polysaccharides, ${ }^{5}$ ribosome and tRNA in bacterial cells, ${ }^{6}$ starch, ${ }^{7}$ gelatin nanoparticle drug carrier systems, ${ }^{8}$ and pullulan ${ }^{9}$ etc.
The aim of this study is to investigate the elution behaviors of pullulan and proteins in an asymmetrical flow FFF (AsFIFFF), in terms of the retention time and the plate height.

\section{Theory}

AsFIFFF theory has been explained in previous publications, and will be briefly reviewed here.

Determination of hydrodynamic diameter $\left(d_{\mathrm{H}}\right)$ by AsFIFFF, In AsFIFFF, the hydrodynamic diameter $\left(d_{\mathrm{H}}\right)$ of a sample is given by

$$
d_{H}=\frac{2 V^{0} k T t_{r}}{\pi \eta w^{2} F_{c} t^{0}}
$$

for highly retained sample..$^{10,11}$ Here $V^{N}$ is the void volume, $k$ the Boltzmann constant, $T$ temperature, $t_{\mathrm{r}}$ retention time, $\eta$ the viscosity of the carrier liquid, $w$ the channel thickness, $F_{\mathfrak{c}}$ the cross-flow rate, and $t^{\circ}$ the void time. Using Eq. (1), the hydrodynamic diameter of a sample can be determined directly from its retention time. The full expression of $\mathrm{Eq}$. (1) is more complicated, ${ }^{12}$ and was used for actual calculation in this study.

Determination of molecular weight by AsFIFFF. Generally for polymers, the relationship between the diffusion coefficient, $D$, and molecular weight, $M$ is expressed by $y^{8.13}$

$$
D=a \cdot M^{-b}
$$


A. Non-equilibrium effect

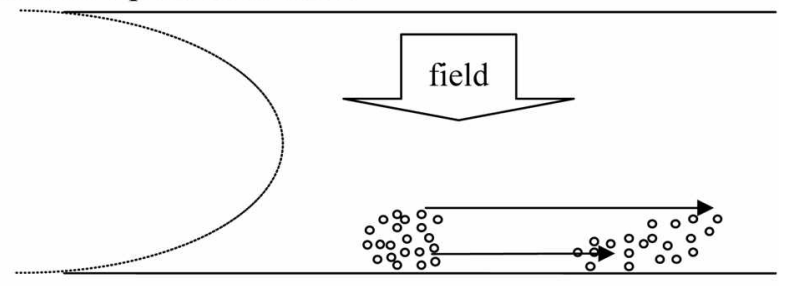

B. Longitudinal diffusion

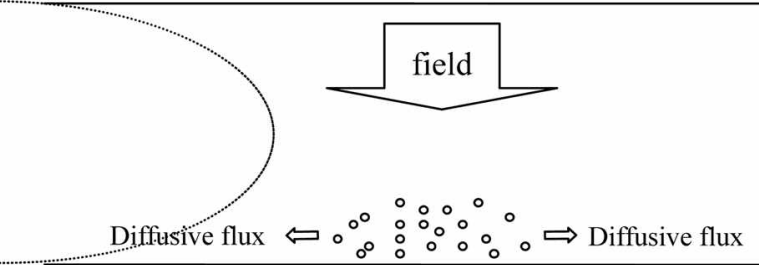

Figure 1. Zone broadening inechanisins in FFF.

, where $a$ and $b$ are constants specific to the polymer/solvent combination. Eq. (2) suggests the relationship between log $D$ and $\log M$ is linear. To determine the molecular weight of a polymer, a calibration plot of $\log D$ and $\log M$ prepared with a series standards of known molecular weight is used. ${ }^{13}$

Plate height $(\mathbf{H})$ in FFF. There are three contributions to zone broadening in FFF. The first is the non-equilibrium contribution expressed by ${ }^{1+, 1}$

$$
H_{n e q}=\frac{\chi_{w^{2}}}{D}\langle v\rangle
$$

where $\langle y\rangle$ is the linear flow velocity and $\chi$ is a tem that can be considered to be a constant at a given condition. ${ }^{15}$ The non-equilibrium effect occurs as the components of the same sample are carried down the channel at different velocities as shown in Figure 1-A. Equation 3 shows the plate height $H$ is proportional to the flow velocity, $\langle v>$.

The second contribution to the zone-broadening is caused by the longitudinal diffusion, and is expressed by ${ }^{16}$

$$
H_{\text {tong }}=\frac{2 D}{R\langle v\rangle}
$$

, where $R$ is the retention ratio, a measure of the sample migration velocity. ${ }^{1.15} R$ increases as the sample migration velocity increases (or the sample is retained less). The longitudinal contribution occurs as the components diffuse out from both the front and the tail of the band due to the axial concentration-gradient as shown in Figure I-B. ${ }^{1}$ The longitudinal contribution is proportional to the diffusion coefficient. This term becomes more serious as the diffusion coefficient of the sample increases. Equation 4 shows $H_{\text {lono }}$ decreases with increasing flow velocity.

The third part is the sum of extraneous contributions including the instrumental effects, which can generally be reduced to negligible levels.

\section{Experimental Section}

The AsFIFFF system was assembled in the laboratory in a
Table 1. Nominal molecular weights and polydispersities of pullulans used in this study

\begin{tabular}{ccc}
\hline & $M_{w}{ }^{4}(\mathrm{Da})$ & $M_{\mathrm{w}} / \mathrm{M}_{\mathrm{H}}{ }^{\mathrm{W}}$ \\
\hline P-10 & $1.22 \times 10^{4}$ & 1.10 \\
P-20 & $2.28 \times 10^{4}$ & 1.07 \\
P-50 & $4.73 \times 10^{4}$ & 1.06 \\
P-100 & $1.12 \times 10^{5}$ & 1.12 \\
P-200 & $2.12 \times 10^{5}$ & 1.13 \\
\hline
\end{tabular}

${ }^{a} M_{\mathrm{w}}$ : weight-average molecular weight, ${ }^{b} M_{\mathrm{w}} / M_{\mathrm{n}}$ : polydispersity index

Table 2. Molccular weights of protcins used in this study

\begin{tabular}{cc}
\hline Protein sample & $M_{\mathrm{w}}(\mathrm{Da})$ \\
\hline$\beta$-lactoglobulin & $3.5 \times 10^{4}$ \\
Ovalbumin & $4.4 \times 10^{4}$ \\
Albumin (BSA) & $6.6 \times 10^{4}$ \\
Ferritin & $4.43 \times 10^{5}$ \\
\hline
\end{tabular}

similar manner as described previously. ${ }^{3.14}$ It is consisted of a trapezoidal channe $1^{14}$ and a membrane having the cut-off molecular weight of $10,000 \mathrm{Da}$. The Mylar spacer has the dimensions of $28.4 \mathrm{~cm}$ in tip-to-tip length and $127 \mathrm{im}$ in thickness, and the maximum breadth of $2 \mathrm{~cm}$ at the inlet. The channel thickness measured from the retention time of Ferritin was $0.0126 \mathrm{~cm}$. Eluted samples were monitored using a Shodex refractive index detector (RI-71, Showa Denko, Toyko, Japan).

Table 1 shows the pullulans used in this study, which were purchased from Showa Denko (Tokyo, Japan). For FFF analysis of pullulans, the carrier was pure water containing $0.02 \% \mathrm{NaN}_{3}$, filtered through a $0.45 \mu \mathrm{m}$ regenerated cellulose filter. The pullulan samples were dissolved in the same liquid as the carrier.

Table 2 shows the proteins used in this study, which were purchased from the Sigma (Sigma chemical, MO, USA). For FFF analysis of proteins, the carrier was pure water containing $0.02 \% \mathrm{NaN}_{3}$ and $0.05 \mathrm{M}$ TRIS-buffer, to which $0.1 \mathrm{M} \mathrm{H}_{3} \mathrm{PO}_{4}$ was added to adjust the $\mathrm{pH}$ to 7.5 .

Calculation of plate height $\mathbf{H}$. For calculation of $H$, the number of the theoretical plates, $N$, was first determined by the half-height method ${ }^{17}$ using

$$
N=5.54\left(\frac{l_{y}}{w_{1 / 2}}\right)^{2}
$$

Then $H$ was obtained by $H=L / N$ where $L$ is channel length.

\section{Results and Discussion}

Figure 2 shows the fractogram of $20 \mathrm{~nm}$ polystyrene (PS) latex beads obtained by AsFIFFF at $F_{\text {cut }}$ and $F_{c}$ of 0.50 and $1.50 \mathrm{~mL} / \mathrm{min}$, respectively. The sample was injected at the flow rate of $24 \mathrm{~mL} / \mathrm{hr}$ for $40 \mathrm{sec}$, and then focused at the flow rate of $1 \mathrm{~mL} / \mathrm{min}$ for $100 \mathrm{sec}$ before the elution of the sample started. The median diameter of the sample determined by AsFIFFF was $18.1 \mathrm{~nm}$. This result suggests AsFIFFF is applicable to determination of the size and its 


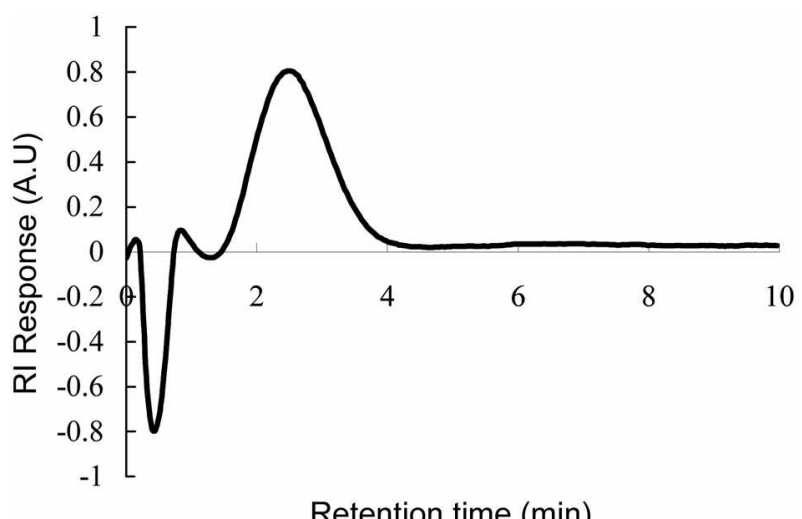

Retention time (min)

Figure 2. $\Lambda$ sFIFFF fractogram of $20 \mathrm{~nm}$ polystyrenc latex beads obtained at $F_{\mathrm{rr}}$ and $F_{\mathrm{c}}$ of 0.50 and $1.57 \mathrm{~mL} / \mathrm{min}$, respectively. Sample was injected at the flow rate of $24 \mathrm{~mL} / \mathrm{hr}$ for $40 \mathrm{sec}$. After the injection, the sample was focused at the flow rate of $1 \mathrm{~mL} / \mathrm{min}$ for $100 \mathrm{sec}$.

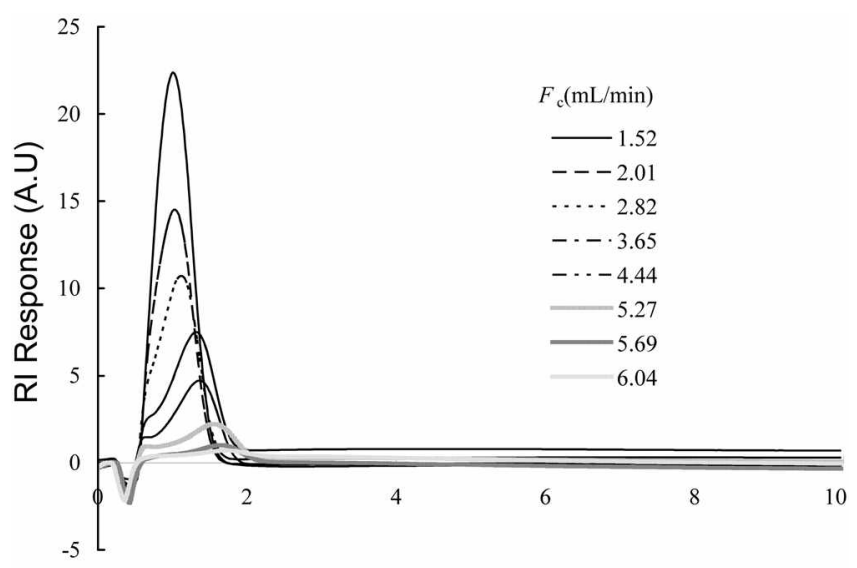

Retention time (min)

Figure 3. Fractograms of pullulan $(\mathrm{P}-10)$ obtained by AsFIFFF at various $F_{\mathrm{c}}$ with $F_{\text {out }}$ fixed constant at $0.50 \mathrm{~mL} / \mathrm{min}$. The sample introduction and focusing conditions were the sane as those in Figure 2 .

distribution of nano-sized colloidal particles. The negative peak at the earlier part of the fractogram in Figure 2 comes from the pressure-pulse caused by the valve turn.

Figure 3 shows a series of fractograms of P-10 (pullulan having the nominal $M$ of $12,200 \mathrm{Da}$ ) obtained by AsFIFFF at various cross-flow rates, $F_{c}$. $F_{\text {ou }}$ was fixed constant at about $0.5 \mathrm{~mL} / \mathrm{min}$. The retention time $\left(t_{r}\right)$, plate height $(H)$, and the diameter $\left(d_{\mathrm{H}}\right)$ determined for the fractograms shown in Figure 3 are summarized in Table 3 . As $F_{c}$ increases, the

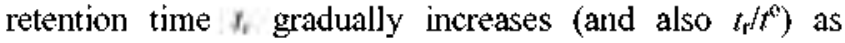
expected. As $F_{c}$ increases, the sample components are pushed more strongly toward the accumulation wall, thus forming an equilibrium layer of smaller thickness, and thus migrate slower. It was also found that the peak area decreases with increasing $F_{c}$, probably due to the sampleloss through the membrane or due to the adsorption of the sample onto the membrane. The nominal molecular weight of the sample $(12,200 \mathrm{Da})$ is close to the cut-off molecular weight of the membrane, which is $10,000 \mathrm{Da}$.
Table 3. AsFIFFF retention, plate height and hydrodynamic diameter of $\mathrm{P}-10$ measured from the fractograms shown in Figure 3

\begin{tabular}{cccccccc}
\hline $\begin{array}{c}F_{\Sigma} \\
(\mathrm{mL} / \mathrm{min})\end{array}$ & $\begin{array}{c}F_{\text {vil }} \\
(\mathrm{mL} / \mathrm{min})\end{array}$ & $F_{\mathrm{c}} / F_{\text {oul }}$ & $\begin{array}{c}t^{\circ} \\
(\mathrm{min})\end{array}$ & $\begin{array}{c}t_{\mathrm{r}} \\
(\mathrm{min})\end{array}$ & $t_{\mathrm{r}} / t^{\circ}$ & $\begin{array}{c}\mathrm{H} \\
(\mathrm{cm})\end{array}$ & $\begin{array}{c}d_{\text {TI }} \\
(\mathrm{nm})\end{array}$ \\
\hline 1.52 & 0.51 & 2.98 & 0.39 & 1.00 & 2.56 & 1.67 & 6.90 \\
2.01 & 0.53 & 3.79 & 0.33 & 1.00 & 3.03 & 1.73 & 6.10 \\
2.82 & 0.53 & 5.22 & 0.28 & 1.07 & 3.82 & 1.80 & 5.73 \\
3.65 & 0.50 & 7.30 & 0.25 & 1.20 & 4.80 & 1.48 & 5.47 \\
4.44 & 0.51 & 8.71 & 0.22 & 1.24 & 5.64 & 1.24 & 5.24 \\
5.27 & 0.52 & 10.13 & 0.20 & 1.41 & 7.05 & 1.70 & 5.66 \\
5.69 & 0.50 & 11.38 & 0.19 & 1.51 & 7.95 & 1.66 & 5.86 \\
6.04 & 0.54 & 11.19 & 0.18 & 1.70 & 9.44 & 9.29 & 6.68 \\
\hline
\end{tabular}

The plate height, $H$ gradually decreases as $F_{\mathrm{c}}$ increases, and reach a minimum $(1.24 \mathrm{~cm})$ at $F_{\mathrm{c}}$ of $4.44 \mathrm{~mL} / \mathrm{in}$, after which $H$ increases. It is interesting that the measured diameter $\left(d_{\mathrm{H}}\right)$ also decreases with increasing $F_{\mathrm{c}}$, reaching a minimum $(5.24 \mathrm{~nm})$ at $F_{\mathrm{c}}$ of $4.44 \mathrm{~mL} / \mathrm{in}$, and then increases. Generally in AsFIFFF, $t_{\mathrm{r}} t t^{\circ} \geq 5$ is recommended for a reasonable amount of retention. ${ }^{18}$ As shown in Table 3, when $F_{\mathrm{c}}$ is less than $3.6, t_{\mathrm{r}} / t^{\circ}$ is smaller than 5 . Thus at $F_{\text {out }}$ of 0.5 $\mathrm{mL} / \mathrm{min}, F_{\mathrm{c}}$ must be higher than about $4 \mathrm{~mL} / \mathrm{min}$. Taking all the results (including the plate height and $t_{\mathrm{r}} / t^{\circ}$ ) into consideration, it can be concluded that $F_{\mathrm{c}}$ of about $4 \mathrm{~mL} / \mathrm{min}$ is an optimum condition for analysis of P- 10 by AsFIFFF. At $F_{\text {c }}$ of 4.44 and $F_{\text {oul }} 0.5 \mathrm{~mL} / \mathrm{min}$ (which is considered to be close to the optimum condition), the hydrodynamic diameter of $\mathrm{P}-10$ was detemnined to be $5.24 \mathrm{~nm}$.

When analyzing water-soluble polymers such as pullulan with AsFIFFF, an effort should be made to find the optimum condition, where the plate height becomes minimal and the sample is retained enough (so that $t_{\mathrm{r}} / t_{0}$ becomes larger than about 5). Otherwise the data (such as the diameter) obtained from AsFIFFF may not be correct. As mentioned above (and as shown in Table 3), the plate height increases after a certain point while the peak area keeps decreasing with increasing $F_{c}$. The back-pressure also increases with increasing $F_{c}$ in AsFIFFF. An optimum condition needs to be found in AsFIFFF by keeping $F_{\mathrm{c}}$ as low as possible as long as the sample is retained enough.

Figure 4 shows the hydrodynamic diameters $\left(d_{\mathrm{H}}\right)$ of the pullulans detemined by AsFIFFF at various cross flow rates $\left(F_{\mathrm{c}}\right)$ at $F_{\text {oul }}$ of $0.5 \mathrm{~mL} / \mathrm{min}$. The sample introduction and focusing conditions were the same as those in Figure 2. The measured diameter $d_{\mathrm{H}}$ varies with $F_{\mathrm{c}}$ for all samples, suggesting again that one needs to find an optimum condition to determine the size with AsFIFFF. In Figure 4, an increase in $d_{\mathrm{H}}$ with increasing $F_{c}$ indicates there may have been adsorption of the sample onto the membrane, while decrease in $d_{\mathrm{H}}$ indicates there is not enough retention. Ideally, one needs to find a region where the measured $d_{\mathrm{H}}$ does not change with conditions.

Figure 5 shows a separation of two pullulans (P-10 and P100 ) obtained by AsFIFFF at two different conditions $\left(F_{\mathrm{c}}\right.$ $=2.7$ or $3.2 \mathrm{~mL} / \mathrm{min}$, while $F_{\text {eut }}$ was fixed at $4 \mathrm{~mL} / \mathrm{min}$ ). The sample introduction and focusing conditions were the same 


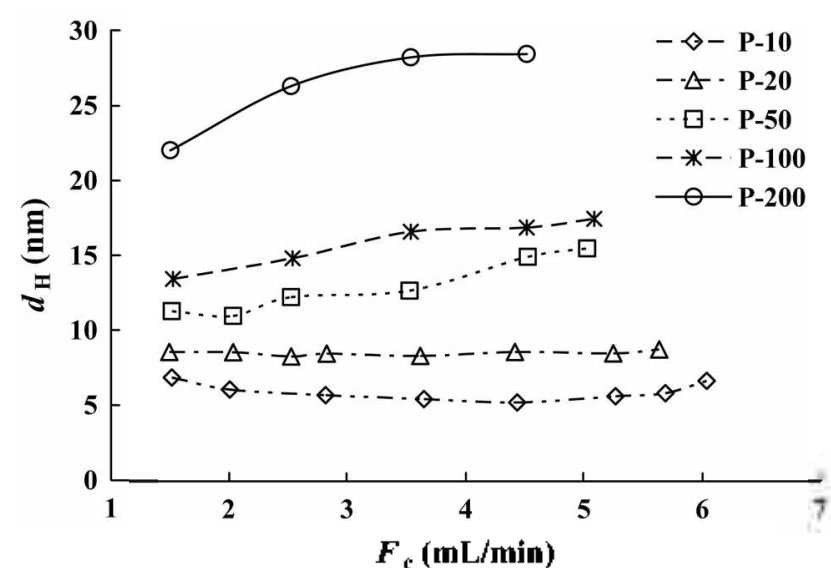

Figure 4. Hydrodynamic diameters of pullulans determined by $\Lambda \mathrm{sFIFFF}$ at various cross flow rates $\left(F_{v}\right)$ with the channcl-out flow rate $\left(F_{\text {oul }}\right)$ fixed constant at about $0.5 \mathrm{~mL} / \mathrm{min}$. The sample introduction and focusing conditions were the same as those in Figure 2.

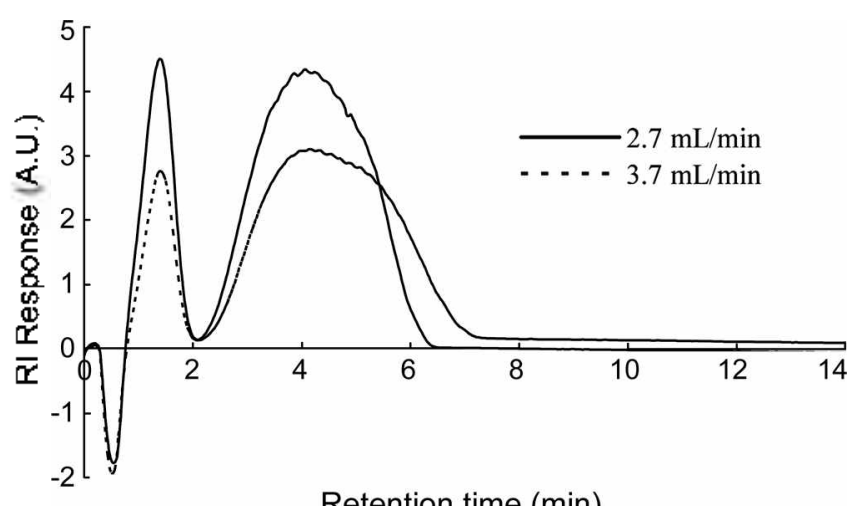

Retention time (min)

Figure 5. Separation of pullulans ( $\mathrm{P}-10$ and $\mathrm{P}-100)$ obtained by AsFIFFF at two different conditions $\left(F_{\mathrm{c}}=2.7\right.$ or $\left.3.2 \mathrm{~mL} / \mathrm{min}\right) F_{\text {out }}$ was same at $4 \mathrm{~mL} / \mathrm{min}$. The sample introduction and focusing conditions were the same as those in Figure 2.

as those in Figure 2. Good separations were obtained at both conditions. The $d_{\mathrm{H}}$ values measured for each peak shown in Figure 5 are summarized in Table 4. Although measured at different conditions, the $d_{H}$ 's measured for the same sample are in good agreement with each other.

Figure 6 shows fractograms of P-100 obtained by AsFIFFF at various $F_{\text {oul }}$ with $F_{\mathrm{c}}$ fixed at about $2.5 \mathrm{~mL} / \mathrm{min}$. The sample concentration was $3 \mathrm{mg} / \mathrm{mL}$ and the sample introduction and focusing conditions were the same as those in Figure 2. The plate height $(H)$, and the hydrodynamic diameter $\left(d_{\mathrm{H}}\right)$ determined for the fractograms shown in Figure 6 are summarized in Table 5. As $F_{\text {oul }}$ increases, the retention time decreases as expected, but the retention level (measured by $t_{\mathrm{r}} / f^{0}$ ) stays almost constant. Also the measured $d_{\mathrm{H}}$, which is determined from the retention data, stays almost constant even though $F_{\text {ou }}$ changes, suggesting the retention data are reliable. On the other hand, the plate height gradually decreases, as $F_{i m}$ increases. This is the tendency expected by the longitudinal diffusion theory (Eq. 4). These results suggest the channel flow rate, $F_{\text {out }}$ needs to be as high
Table 4. Hydrodynamic diameters of P-10 and P-100 measured from the fractograms shown in Figure 5

\begin{tabular}{|c|c|c|c|c|c|c|c|c|}
\hline $\begin{array}{c}F_{\mathrm{c}} \\
(\mathrm{mL} / \mathrm{min})\end{array}$ & $\begin{array}{c}F_{i s s} \\
(n L / \min )\end{array}$ & $F_{\mathrm{c}} / F_{\text {out }}$ & $t^{\circ}$ & & $\begin{array}{c}t_{5} \\
(\mathrm{~min})\end{array}$ & $\underset{(\mathrm{con})}{\mathrm{H}}$ & $t_{\mathrm{r}} / t^{0}$ & $\begin{array}{c}d_{\uparrow \mathrm{T}} \\
(\mathrm{nm})\end{array}$ \\
\hline \multirow[t]{2}{*}{2.72} & 0.37 & 7.35 & 0.33 & P-10 & 1.36 & 1.17 & 4.12 & 6.16 \\
\hline & & & & $P-100$ & 4.22 & 1.98 & 12.8 & 19.8 \\
\hline \multirow[t]{2}{*}{3.20} & 0.40 & 8.00 & 0.29 & P- 10 & 1.38 & 1.07 & 4.76 & 6.07 \\
\hline & & & & P- 100 & 4.56 & 2.69 & 15.7 & 20.7 \\
\hline
\end{tabular}

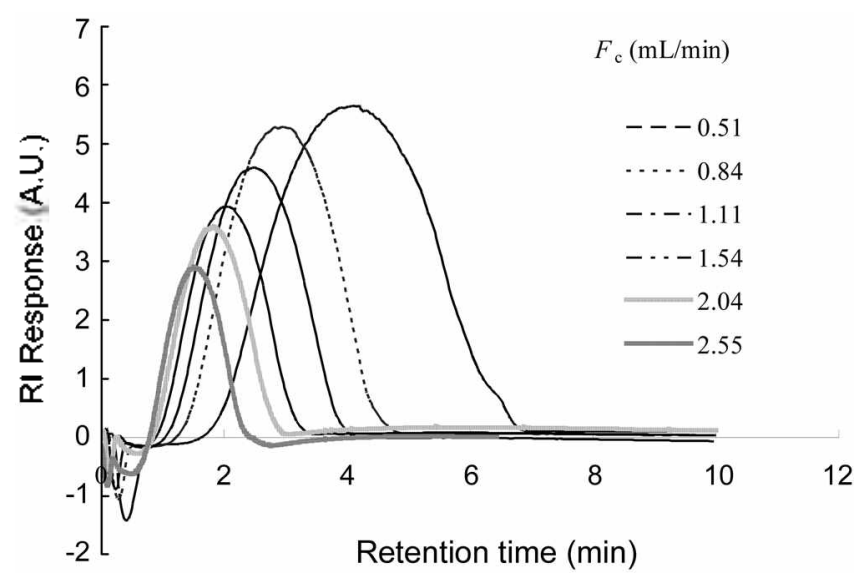

Figure 6. Fractograms of P-100 obtained by AsFIFFF at various $F_{o s}$ with $F_{\mathrm{c}}$ fixed at about $2.5 \mathrm{~mL} / \mathrm{min}$. The sample concentration was $3 \mathrm{mg} / \mathrm{mL}$ and the sample introduction and the focusing conditions were the same as those in Figure 2.

Table 5. AsFIFFF retention, plate height and size of $\mathrm{P}-100$ measured for the fractograns shown in Figure 6

\begin{tabular}{cccccc}
\hline $\begin{array}{c}F_{\mathrm{c}} \\
(\mathrm{mL} / \mathrm{min})\end{array}$ & $\begin{array}{c}F_{\mathrm{cut}} \\
(\mathrm{mL} / \mathrm{min})\end{array}$ & $F_{\mathrm{v}} / F_{\text {out }}$ & $\begin{array}{c}I I \\
(\mathrm{~cm})\end{array}$ & $t_{\mathrm{t}} / t^{\circ}$ & $\begin{array}{c}d_{\mathrm{T}} \\
(\mathrm{nm})\end{array}$ \\
\hline 2.51 & 0.21 & 12.0 & 3.12 & 15.8 & 25.5 \\
2.52 & 0.51 & 4.94 & 2.70 & 13.8 & 23.2 \\
2.49 & 0.84 & 2.96 & 2.48 & 12.2 & 22.1 \\
2.53 & 1.11 & 2.28 & 2.45 & 12.6 & 21.5 \\
2.50 & 1.54 & 1.23 & 2.44 & 12.9 & 21.8 \\
2.53 & 2.04 & 1.24 & 2.20 & 14.1 & 23.3 \\
2.50 & 2.55 & 0.98 & 2.19 & 14.0 & 22.6 \\
\hline
\end{tabular}

as possible to reduce the zone broadening. This will also allow reduction in analysis time. It is noted however that appropriate level of retention needs to be maintained with $t_{\mathrm{r}} / t^{\circ}$ higher than about $5^{18}$

Figure 7 shows the fractograms of P-100 obtained by AsFIFFF at various $F_{i=}$ with $F_{\mathrm{c}} / F_{\text {oul }}$ fixed constant at about 5 . All the experimental conditions were the same as those in Figure 6 . The plate height $(H)$, and the hydrodynamic diameter $\left(d_{H}\right)$ determined for the fractograms shown in Figure 7 are summarized in Table 6. As $F_{\text {i increases, both }}$ $F_{\mathrm{c}}$ and $F_{\text {ou }}$ increase, and the retention level $\left(t_{\mathrm{r}} / t^{\circ}\right)$ increases while the retention time stays almost constant as shown in Figure 6 and in Table 6 . The measured $d_{\mathrm{H}}$ again stays almost constant even though experimental condition changes. On the other hand, the plate height gradually increases as $F_{\text {in }}$ 


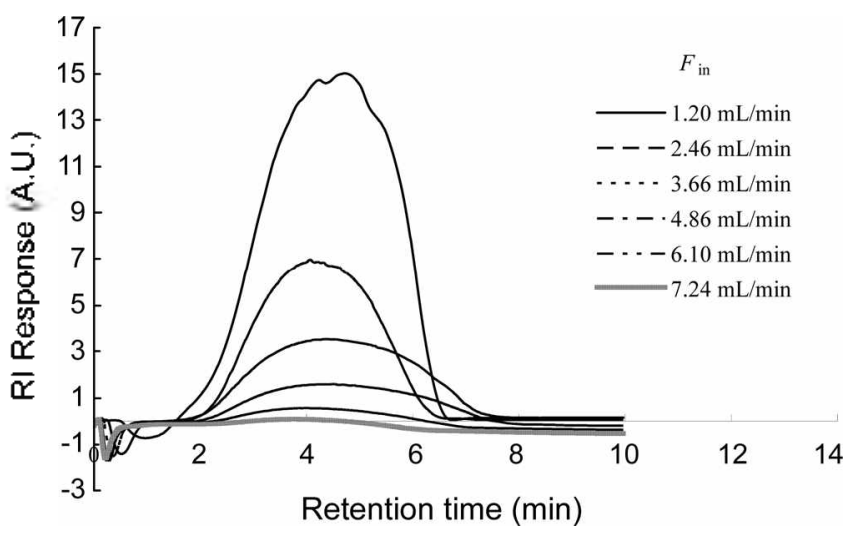

Figure 7. Fractograms of $\mathrm{P}-100$ obtained by $\Lambda \mathrm{sFIFFF}$ at various $F_{n}$ with $F_{\mathrm{i}} / F_{\text {ou }}$ fixed constant at about 5 . All experimental conditions were the same as those in Figure 6.

Table 6. $\Lambda$ SFIFFF retention, plate height and size of P-J00 measured for the factograins shown in Figure 7

\begin{tabular}{cccccc}
\hline $\begin{array}{c}F_{\mathrm{s}} \\
(\mathrm{mL} / \mathrm{min})\end{array}$ & $\begin{array}{c}F_{w 4} \\
(\mathrm{~mL} / \mathrm{min})\end{array}$ & $F_{\mathrm{s}} / F_{\text {volt }}$ & $\begin{array}{c}\mathrm{H} \\
(\mathrm{cm})\end{array}$ & $b / i^{\circ}$ & $\begin{array}{c}d_{\mathrm{T}} \\
(\mathrm{nm})\end{array}$ \\
\hline 1.01 & 0.20 & 5.05 & 2.06 & 5.78 & 21.9 \\
2.08 & 0.38 & 5.47 & 2.33 & 10.8 & 20.6 \\
3.06 & 0.60 & 5.10 & 3.63 & 18.4 & 24.2 \\
4.06 & 0.80 & 5.08 & 3.69 & 24.7 & 25.6 \\
5.09 & 1.01 & 5.04 & 3.44 & 29.2 & 24.0 \\
6.04 & 1.20 & 5.03 & 6.58 & 31.2 & 22.2 \\
\hline
\end{tabular}

increases. This is the tendency expected by the "nonequilibrium effect" theory ( $\mathrm{Eq} .3$ ), which results in the plate height increasing with the flow rate. However, in this case, the increase in plate height is not caused only by the nonequilibrium effect. Rather, it is affected more by the increase in retention by the increase in $F_{\mathrm{c}}$. These results suggest, when $F_{\mathrm{d}} / F_{\text {out }}$ is kept constant, $F_{\text {in }}$ needs to be as low as possible to reduce the zone broadening.

Figure 8 shows calibration plots of pullulan obtained at various $F_{c}$. $F_{\text {out }}$ was fixed constant at about $2.5 \mathrm{~mL} / \mathrm{min}$. The carrier was pure water containing $0.02 \% \mathrm{NaN}_{3}$. The plot-e in Figure 8 was obtained using the diffusion coefficients from a literature, ${ }^{19}$ which was measured by the dynamic light scattering (DLS). At low $M_{\text {, all experimental plots agree }}$ well with the plot-e. The deviation increases with increasing $M$. In Figure 8, the diffusion coefficients were determined from the retention time measured at the median of the peaks.

To test the pullulan-calibration plots shown in Figure 8, the BSA (having the nominal $M$ of 66,000 ) was injected at $F_{\text {oul }}$ of 0.418 and $F_{\mathrm{c}}$ of $2.16 \mathrm{~mL} / \mathrm{min}$. With the calibration plot shown in Figure 8, the molecular weight of BSA was measured to be 13,300 . This difference is probably due to the difference in molecular conformation between pullulan and BSA. Pullulan is water-soluble microbial polysaccharide. It consists of I-6-linked maltotriose units and has a linear structure. ${ }^{20}$ But the proteins are made up of amino acid units linked together. Amino acids contain both a basic amino group and an acidic carboxyl group. Proteins exist as

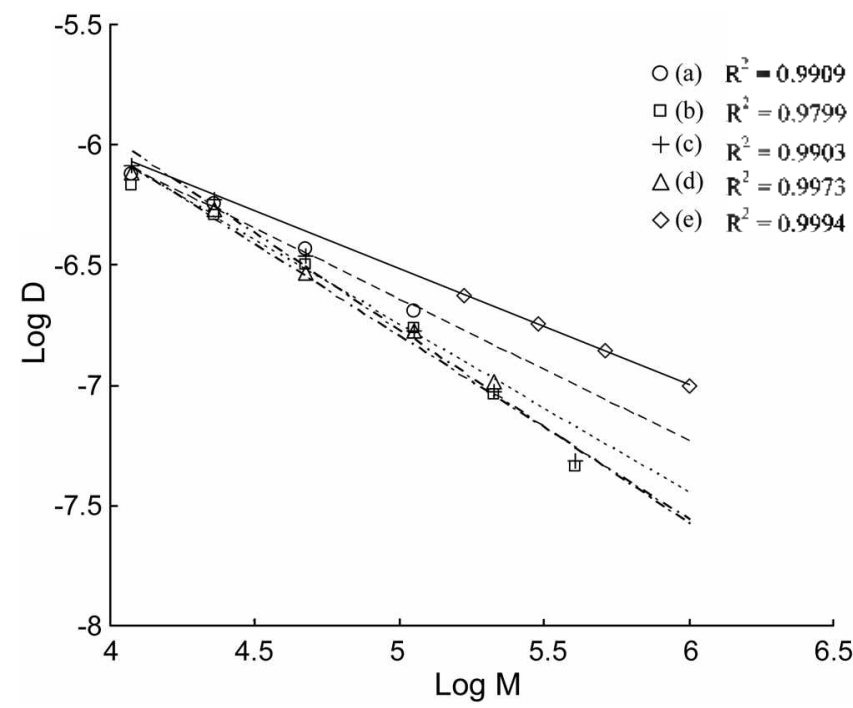

Figure 8. AsFIFFF calibration plots of pullulan obtained at various $F_{\mathrm{c}}$ with $F_{\text {out }}$ fixed constant at about $2.5 \mathrm{~mL} / \mathrm{min} . F_{\mathrm{c}}=2.6$ (a) 3.2 (b), 4.0 (c) and $5.0 \mathrm{~mL} / \mathrm{min}$ (d), respectively. $t_{1}$ was measured at the median of the peak. The literature values were used for the plote-

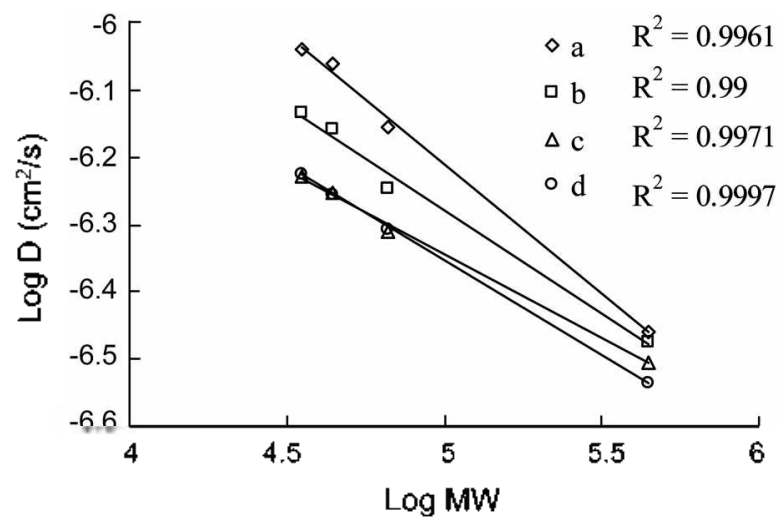

Figure 9. $\Lambda$ SFIFFF calibration plots of proteins obtained at various $F_{\text {oul }} F_{d} / F_{\text {oul }}$ was fixed constant at $12 . F_{\text {oul }}$ was $0.5(\mathrm{a}), 0.3$ (b), and $0.2 \mathrm{~mL} / \mathrm{min}$ (c), respectively. Calibration plot of proteins obtained in a Tris buffer $(\mathrm{pH}=7.5) . F_{\mathrm{c}} / F_{\text {out }}$ was 12 and $F_{\text {out }}$ was $0.2 \mathrm{~mL} / \mathrm{min}$ (d).

either globular or fibrous. Fibrous proteins are insoluble, while globular proteins are soluble." BSA is a globular protein. ${ }^{1-23}$

Figure 9 shows calibration plots of proteins obtained at various $F_{\text {iut }} . F_{\mathrm{c}} / F_{\text {cut }}$ was fixed constant at $12 . F_{\text {cut }}$ was 0.5 , 0.3 , and $0.2 \mathrm{~mL} / \mathrm{min}$ in Figure 9-a, $b$, and $c$, respectively. Proteins are zwitterions, ${ }^{21}$ and thus its elution behavior will change with $\mathrm{pH}$. The plot-d in Figure 9 was obtained at $\mathrm{pH}$ of 7.5 (adjusted with a TRIS buffer) as suggested by a previous work. ${ }^{4}$ The $R^{2}$ of calibration curve is 0.9997 , which is better than those for other plots. With the calibration plote, the molecular weight of BSA was measured to be 68,000 .

\section{Conclusion}

The results of this study show the capability of AsFIFFF 
for size-based separation of water-soluble or biological macromolecules. When analyzing water-soluble polymers such as pullulans or biopolymers such as proteins with AsFIFFF, an effort should be made to find an optimum condition, where the plate height becomes minimal and the sample is retained enough (so that $t_{5} / t_{0}$ becomes larger than about 5). Otherwise the data obtained from AsFIFFF may not be correct.

When tested with $\mathrm{P}-100$, the plate height $H$ in AsFIFFF decreases with increasing $F_{\text {out }}$ when $F_{\mathrm{c}}$ was fixed constant. This is the trend expected by the "longitudinal diffusion" theory. Results suggest the channel flow rate, $F_{\text {out }}$ needs to be as high as possible to reduce the zone broadening, as long as an appropriate level of retention is maintained. The results

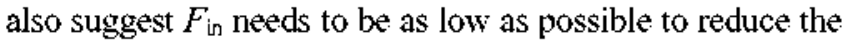
zone broadening.

The calibration plots $(\log D$ vs. $\log M$ ) obtained from pullulans and proteins were different, indicating analysis of pullulans and proteins require independent calibration. The linearity of the protein-calibration plot was improved by the use of a buffer.

Acknowledgements. This work was supported by the Korea Research Foundation Grant funded by the Korean Govemment (MOEHRD) (R05-2004-000-12516-0). Some of authors were supported by the $2^{\text {nd }}$ stage $\mathrm{BK} 21$ project.

\section{References}

1. Giddings, J. C. Unified Separation Science; Wiley-Interscience: New York, 1991 .

2. Nilsson, M.; Bimbaum, S.; Wahlund, K.-G. J. Biochem. Biophys. Methods 1996, 33, 9-23.

3. Wahlund, K.-G; Giddings, J. C. Anal. Chen 1987, 59, 1332-1339.

4. Song, J.-H.; Kim, W.-S.; Park, Y.-H.; Yu, E.-K.; Lee, D. W. Bull.
Korean Chem. Soc. 1999, 20(10), 1159-1164.

5. Wittgren, B.; Wahlund, K.-G. J. of Chromato. A 1997, 760, 205218.

6. Arfvidsson, C.; Wahlund, K.-G Anat. Biochem. 2003, 3/3, 76-85.

7. Fraunholer, W; Winter, G; Coester, C. Anal. Chem. 2004, 76, 1909-1920.

8. Benincasa, M.-A.; Fratle, C. D. J. of Chomatogr: A 2004, 1046, $175-184$.

9. Lee, S.; Nilsson, P.-O.; Nilsson, G. S.; Wahlund, K.-G. J. of Chromalogr $A$ 2003, J0H, 111 1-123.

10. Wittgren, B.; Wahlund, K.-G; Derand, H.; Wesslen, B. Macromolecules 1996, 29, 268-276.

11. Wahlund, K.-G; Gustavsson, M.; MacRitchie, F.; Nylander, T.; Wannerberger, L. J. of Cereal Science 1996, 23, I13-1 19.

12. Schure, M. R.; Schimpf, M. E.; Schettler, P. D. Field Flow Fractionation Handbook, Schimpl, M. E.; Caldwell, K. D.; Giddings, J. C.. Eds.; Wiley-Interscience: New York, 2000, pp 31 48.

13. Benincasa, M.-A.; Caldwell, K. D. J. of Chronatogr, $A$ 2001, 925 , 159-169.

14. Litzen, A.; Wahlund, K.-G. Anal. Chem. 1991, 63, 1001-1007.

15. Davis, J. M. Field Flow Fractionation Hantbook, Schimpf, M. E.; Caldwell, K. D.; Giddings, J. C., Eds.; Wiley-Interscience: New York, $2000 ;$ pp 49-70.

16. Litzen, A. Anal. Chem. 1993, 65, 461-470.

17. Christian, G. D. Analytical Chemistry; John Wiley \& Sons: New York, U. S. A., 1994; p 5 II.

18. Wahlund, K.-G. Field Flow Fractionation Handbook; Schimpf, M. E.; Caldwell, K. D.; Giddings, J. C., Eds.; Wiley-Interscience: New York, 2000; pp 279-294.

19. Polymer Handbook, $4^{\text {th }}$ Ed-2; Brandrup, J.; Immergut, E. H.; Grulke, E. A., Eds.; John Wiley \& Sons, Inc.: New York, U.S.A., $1999 ; \mathrm{p} \mathrm{VII/150.}$

20. Wittgren, B.; Wahlund, K.-G. J. Chronlatogr, $A$ 1997, 760, 205. 218 .

21. McMurry, J. Organic Chemistry, 51h Ed.; Book/Cole: USA, 2000; chapter 26.

22. Carter, D.; Chang, B.; Ho, J. X.; Keeling, K.; Krishnasami, Z. Eur J. Biochem. 1994, 226, 1049 .

23. He, X. M.; Carter, D. C. Nattre 1992, 358, 209 